\title{
Halogen-induced organic aerosol (XOA): a study on ultra-fine particle formation and time-resolved chemical characterization
}

\author{
Johannes Ofner, ${ }^{* a}$ Katharina A. Kamilli, ${ }^{\text {b }}$ Andreas Held, ${ }^{\text {b }}$ \\ Bernhard Lendl ${ }^{a}$ and Cornelius Zetzsch ${ }^{c}$
}

Received 20th May 2013, Accepted 31st May 2013

DOI: $10.1039 / \mathrm{c3fd00093a}$

The concurrent presence of high values of organic SOA precursors and reactive halogen species (RHS) at very low ozone concentrations allows the formation of halogen-induced organic aerosol, so-called XOA, in maritime areas where high concentrations of RHS are present, especially at sunrise. The present study combines aerosol smog-chamber and aerosol flow-reactor experiments for the characterization of XOA. XOA formation yields from $\alpha$-pinene at low and high concentrations of chlorine as reactive halogen species (RHS) were determined using a $700 \mathrm{~L}$ aerosol smog-chamber with a solar simulator. The chemical transformation of the organic precursor during the aerosol formation process and chemical aging was studied using an aerosol flow-reactor coupled to an FTIR spectrometer. The FTIR dataset was analysed using 2D correlation spectroscopy. Chlorine induced homogeneous XOA formation takes place at even $2.5 \mathrm{ppb}$ of molecular chlorine, which was photolysed by the solar simulator. The chemical pathway of XOA formation is characterized by the addition of chlorine and abstraction of hydrogen atoms, causing simultaneous carbon-chlorine bond formation. During further steps of the formation process, carboxylic acids are formed, which cause a SOAlike appearance of XOA. During the ozone-free formation of secondary organic aerosol with RHS a special kind of particulate matter (XOA) is formed, which is afterwards transformed to SOA by atmospheric aging or degradation pathways.

\section{Introduction}

Secondary organic aerosol (SOA) formation is currently mainly discussed pertaining to reactions of common atmospheric trace-gases like $\mathrm{OH}, \mathrm{O}_{3}$ and $\mathrm{NO}_{x}$ with a large variety of organic precursors. A review by Kroll and Seinfeld ${ }^{1}$ summarizes $^{2}$

\footnotetext{
${ }^{a}$ Institute of Chemical Technologies and Analytics, Environmental and Process Analytics Division, Vienna University of Technology, Getreidemarkt 9, 1060 Vienna, Austria.E-mail: johannes.ofner@tuwien.ac.at ${ }^{b}$ Junior Professorship in Atmospheric Chemistry, University of Bayreuth, Dr Hans-Frisch-Strasse 1-3, 95448 Bayreuth, Germany

${ }^{c}$ Atmospheric Chemistry Research Laboratory, University of Bayreuth, Dr Hans-Frisch-Strasse 1-3, 95448 Bayreuth, Germany
} 
this common understanding of SOA formation initiated by gas-phase oxidation and followed by particle-phase reactions involving the above mentioned atmospheric reactants. The evolution of organic aerosols in the atmosphere and the chemical transformation to aged organic aerosol is generally related to the presence of $\mathrm{OH}$ radicals or ozone. ${ }^{2}$ Recently, Riipinen et al. ${ }^{3}$ proposed that the condensation of low-volatility vapours and the formation of organic salts dominate the first steps in growth of ultra-fine organic particles. Over the open ocean and in marine environments, organic precursor gases, such as volatile halocarbons, are thought to contribute to marine aerosol formation., ${ }^{4,5}$

Apart from this general approach towards SOA formation with a major contribution of ozone and $\mathrm{OH}$ radicals, a few publications cover the topic of halogen-induced formation of SOA. The kinetics of the gas-phase reaction of monoterpenes with atomic chlorine have been studied e.g. by Timerghazin and Ariya, ${ }^{6}$ implying higher reaction rates of $\mathrm{Cl}$ with selected monoterpenes compared to the $\mathrm{OH}$-initiated reaction. They called for further research of the possible impact on the chlorine-initiated oxidation related to aerosol formation. For chlorine-induced aerosol formation from toluene with chlorine and toluene concentrations in the range of several $10^{16}$ molecules $\mathrm{cm}^{-3}$, particle concentrations up to $3.5 \times 10^{8} \mathrm{~cm}^{-3}$ are reported. ${ }^{7}$ Cai and Griffin ${ }^{8}$ report the formation of halogen-induced SOA from different monoterpenes by chlorine atoms using an aerosol smog-chamber. These authors state that the chlorine-induced SOA formation is generally comparable to other scenarios and conclude that the chlorine-initiated oxidation of monoterpenes could be a source of SOA at sunrise. A similar study by these authors arrives at the same conclusion for the chlorineinitiated oxidation of toluene. ${ }^{9}$ Kroll and Seinfeld ${ }^{1}$ mention the chlorine-initiated SOA formation but conclude that it has a smaller effect on the vapour pressure than caused by $\mathrm{OH}$ radicals. A physico-chemical characterization of organic aerosol model substances, processed by reactive halogen species (RHS), considering the difference between halogen-induced organic aerosol and pre-existing SOA, which is processed by RHS during the period of photochemical aging is given by Ofner et al. ${ }^{10}$ This study concludes a similar way of interaction of halogens with organic precursors as found by Kroll et al. ${ }^{11}$ Other halogen species containing bromine and iodine are also suspected to significantly contribute to aerosol formation and processing. ${ }^{12-14}$ Lifetimes of monoterpenes can be significantly influenced by halogens at dawn, where the reaction of chlorine atoms becomes comparable to the reaction with $\mathrm{OH}$ radicals. ${ }^{15}$

Halogen-induced organic aerosol formation is strongly dependent on the available concentration of RHS. RHS represent an abundant class of atmospheric oxidants in maritime areas. The importance of chlorine atoms as a tropospheric oxidant in the marine boundary layer was discussed in $1993,{ }^{16}$ concluding that the photochemical oxidation of organics by chlorine could exceed the importance of $\mathrm{OH}$ under special conditions. Unexpectedly high chlorine concentrations are reported by Spicer et al. ${ }^{17}$ These authors report $\mathrm{Cl}_{2}$ mixing ratios between 10 and $150 \mathrm{ppt}$ and conclude that an unknown chlorine source must exist, which produces up to $330 \mathrm{ppt} \mathrm{Cl}_{2}$ per day. A recent review summarizes very high chlorine mixing ratios: ${ }^{18} 200 \mathrm{ppt}$ for $\mathrm{Cl}_{2}$, up to $421 \mathrm{ppt}$ for $\mathrm{Cl}_{2}$ and $\mathrm{HOCl}, 5.6 \mathrm{ppb}$ for $\mathrm{HCl}$ and up to $2.1 \mathrm{ppb}$ for $\mathrm{ClNO}_{2}$. Different sources of RHS are reported in the scientific literature. Early smog-chamber experiments expected a possible release of molecular chlorine by homogeneous and heterogeneous reactions of different 
halogen sources like salts or acids. ${ }^{19}$ The heterogeneous tropospheric chemistry of sea salt aerosol is known as an important source of RHS to the marine boundary layer. ${ }^{20}$ The formation of $\mathrm{ClNO}_{2}$ in the night-time and photolysis to $\mathrm{Cl}$ radicals and $\mathrm{NO}_{2}$ during sunrise is reported as a large atomic chlorine source. ${ }^{21}$

The abundance of RHS in the marine boundary layer could contribute significantly to organic aerosol formation, especially at dawn and sunrise, when night-time reservoir substances are photolysed and ozone levels are still low. The present study reports aerosol-formation experiments from $\alpha$-pinene with chlorine atoms. Furthermore, the chemical transformation of the organic precursor was studied using an aerosol-flow reactor coupled to an FTIR spectrometer and interpreted using 2D correlation spectroscopy ${ }^{22}$ to obtain synchronous and asynchronous sequential mechanistic information.

\section{Methods}

\section{Aerosol smog-chamber setup and experiments}

Aerosol formation experiments were performed using a $700 \mathrm{~L}$ aerosol smogchamber. Details on this chamber can be found at Ofner et al. ${ }^{23}$ The smog chamber is equipped with a solar simulator (Osram, HMI, $4000 \mathrm{~W}$ ). $\mathrm{NO}_{2}$ actinometry, as reported by Bohn et al. ${ }^{24}$ was used to determine the spectral actinic flux, which is shown in Fig. 1 and compared to the solar actinic flux at the Mediterranean Sea in summer. This solar actinic flux was calculated using the STARsci v2.1 software package. ${ }^{25}$ The solar simulator allows simulation of a solar spectrum comparable to that above the Mediterranean Sea in summer (Fig. 1). Based on the measurement of the spectral actinic flux, the photolysis of molecular chlorine was calculated inside the aerosol smog-chamber with a photolysis rate of $j_{\mathrm{Cl}_{2}}=1.89 \times 10^{-3} \mathrm{~s}^{-1}$.

Before the experiments, the chamber was flushed with purified zero-air to avoid contamination of the chamber with aerosols or organic trace gases. ${ }^{23}$ Zero

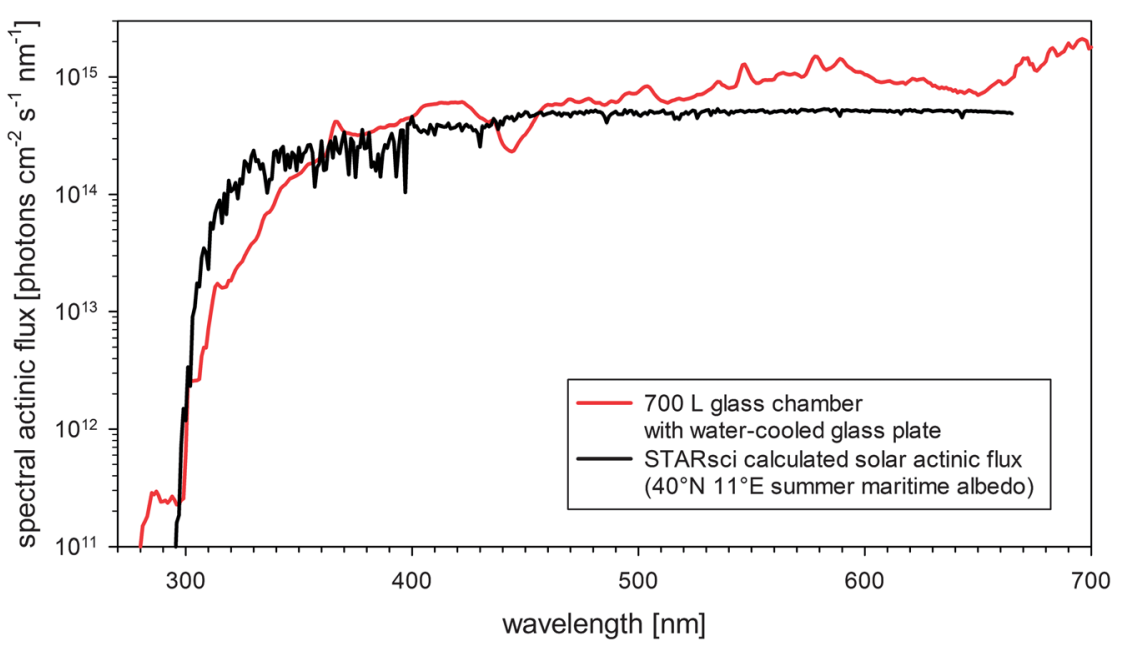

Fig. 1 The spectral actinic flux of the solar simulator of the aerosol smog-chamber compared to the solar actinic flux at the Mediterranean Sea in summer (calculated using STARsci v2.125). 
air was also used to keep the pressure inside the chamber above ambient conditions during the experiments. Therefore, all experimental data were corrected for dilution and wall-loss. Background measurements determined a dilution rate for the organic precursor of $3.2 \times 10^{-3} \mathrm{~min}^{-1}$. Ozone concentrations were measured using a chemiluminescence ozone analyser (Bendix-UPK8002; Bad Nauheim, Germany), exhibiting photolytically formed ozone concentrations below $10 \mathrm{ppb} . \mathrm{NO}_{2}$ and NO concentrations were monitored using a CLD-700-Al analyser (Ecophysics, Dürnten, Switzerland) to ensure low- $\mathrm{NO}_{x}$ conditions (below $10 \mathrm{ppb}$ ). A GC-FID system with an RTX resin column and a homemade cryostatic preconcentrator was applied to measure the decay of the organic precursor with a temporal resolution of $10 \mathrm{~min}$. The aerosol number and size distribution was measured using a custom-built SMPS (IfT Leipzig, Germany) coupled to a TSI 3772 condensation particle counter (TSI, Shoreview, MN, USA). The aerosol mass formed at time $t, M_{t}$, was calculated from the measured aerosol size distributions assuming spherical particles and a particle density of $1.25 \mathrm{~g} \mathrm{~cm}^{-3}$. Aerosol size distributions were corrected for wall-loss according to Pathak et al. ${ }^{26}$ assuming a first-order wall-loss rate determined from plotting $\ln \left(M_{t}\right)$ against time after aerosol mass production has stopped. For size-dependent wall-loss corrections, we adjusted the formula of Crump and Seinfeld ${ }^{27}$ for an arbitrary vessel to our cylindrically shaped smog chamber, and chose the turbulent energy dissipation parameter $k_{\mathrm{e}}$ in a way that the total aerosol mass derived from the size-dependent wall-loss correction was consistent with the integral wall-loss correction. Fig. 2a demonstrates a typical evolution of the aerosol size distribution from a chamber experiment related to XOA formation. The temporal evolution of aerosol mass before and after application of the wall-loss correction is shown in Fig. 2 b.

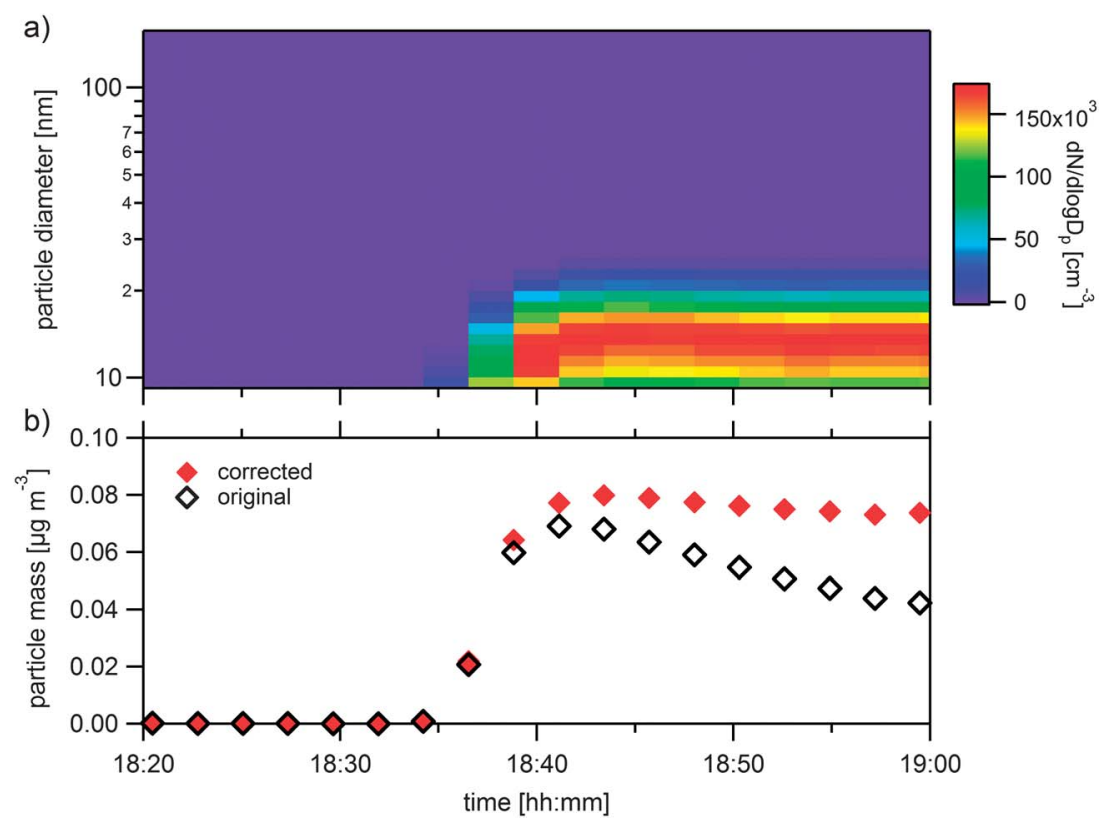

Fig. 2 a) Aerosol size distribution for a chamber experiment with $\boldsymbol{\alpha}$-pinene and photolyzed molecular chlorine; b) aerosol mass concentration resulting from the original and corrected SMPS data. 
Table 1 Initial conditions, aerosol mass $\Delta M_{0}$ and aerosol mass yield $Y$ of smog-chamber runs

\begin{tabular}{lclll}
\hline Experiment & $\mathrm{Cl}_{2}[\mathrm{ppb}]$ & $\alpha$-pinene $[\mathrm{ppb}]$ & $\Delta M_{0}\left[\mu \mathrm{g} \mathrm{m}^{-3}\right]$ & $Y$ \\
\hline Cl-1 & 2.5 & 10 & $1.3 \times 10^{-3}$ & $3.7 \times 10^{-5}$ \\
Cl-2 & 5 & 10 & $6.0 \times 10^{-2}$ & $2.0 \times 10^{-3}$ \\
Cl-3 & 5 & 10 & $6.4 \times 10^{-2}$ & $9.8 \times 10^{-3}$ \\
Cl-4 & 20 & 20 & 23.7 & $2.4 \times 10^{-1}$ \\
Cl-5 & 100 & 20 & 12.4 & $1.1 \times 10^{-1}$ \\
Cl-6 & 200 & 50 & 175.7 & $6.2 \times 10^{-1}$
\end{tabular}

Aerosol formation experiments were started by switching on the solar simulator at zero-air conditions. After establishing a constant spectral actinic flux, $\alpha$-pinene (Sigma-Aldrich, purity of $98 \%$ ) was injected into the chamber. The concentration of the organic precursor was adjusted by injecting a known volume of the saturated vapour from the organic species. Two GC background measurements (20 min) were performed to monitor the homogeneous distribution of the precursor inside the aerosol smog-chamber and to obviate self-initiated aerosol formation. The aerosol formation was initiated by injection of a known volume of $1 \%$ molecular chlorine, diluted in $\mathrm{N}_{2}$ (Linde, Germany) into the chamber. Table 1 summarizes the experimental conditions of the aerosol smogchamber runs.

\section{Aerosol flow-reactor setup and experiments}

To study the chemistry of the halogen-induced organic aerosol formation, an aerosol flow-reactor was set up and coupled to a Bruker IFS 113v FTIR spectrometer, which is equipped with a normal pressure sample compartment. The sample compartment is separated from the vacuum system of the FTIR spectrometer using two $\mathrm{KBr}$ windows. A circular multi-reflection cell ${ }^{28}$ with path lengths up to $105 \mathrm{~cm}$ was installed inside the sample compartment and coupled to the flow reactor. The flow reactor itself is described in detail by Ofner et al., $2010 .{ }^{29}$ Additionally, the lamps of a common UV face tanner (Philips UVA Typ HP $3151 / \mathrm{A}$ ), with an emission characteristic between 270 and $450 \mathrm{~nm}$ and a maximum power of $1 \mathrm{~W} \mathrm{~m}^{-2} \mathrm{~nm}^{-1}$, were placed around the flow-reactor for photolysis of molecular chlorine. Three mass-flow controllers (MFC) were used to control the flow conditions within the flow reactor. The sheath and reactive gasflow were mixed using two 2000 sccm MFCs from zero-air and $1 \% \mathrm{Cl}_{2}$ in $\mathrm{N}_{2}$ and fed to the top of the aerosol flow-reactor itself. Zero-air was saturated with the organic precursor ( $\alpha$-pinene - 500 Pa vapour pressure) and injected into the moveable inlet of the flow reactor. The XOA formation was initiated depending on

Table 2 Flow conditions and mixing ratios within the aerosol flow-reactor

\begin{tabular}{lllll}
\hline Condition & $\mathrm{Cl}_{2}[\mathrm{Vol} \%]$ & $\alpha$-pinene $[\mathrm{ppm}]$ & total flow $[\mathrm{sccm}]$ & max. reaction time $[\mathrm{s}]$ \\
\hline A & 0.44 & 85 & 600 & 8.5 \\
$\mathrm{~B}$ & 0.35 & 67 & 750 & 6.7 \\
$\mathrm{C}$ & 0.60 & 116 & 445 & 11.5 \\
$\mathrm{D}$ & 0.84 & 161 & 316 & 16.0
\end{tabular}


the position of the moveable inlet, where mixing of the organic vapour and the RHS occurred. The flow conditions and resulting available reaction times are shown in Table 2 . The flow reactor was operated at slightly reduced pressure to avoid contamination of the multi-reflection cell and the reactor itself with lowvolatile species or aerosol particles. The applied flow rates allowed an operation of the reactor under laminar conditions.

For FTIR spectroscopy, 256 scans with a resolution of $4 \mathrm{~cm}^{-1}$ in the range $4000-600 \mathrm{~cm}^{-1}$ were recorded. Spectra were recorded at 5, 10, 20, 30, and $40 \mathrm{~cm}$ distance of the inlet to the centre of the multi-reflection cell. Background measurements were performed when the flow reactor was flushed with zero air. The raw spectra were background corrected using the Bruker Opus 7.0 software package because of a strong contribution of Mie scattering of aerosol particles to the absorbance spectra. Further, absorptions of $\mathrm{CO}_{2}$ at 2349 and $667 \mathrm{~cm}^{-1}$ were corrected to zero at the lowest stage of the reactor for series A. To allow a clear demonstration of the obtained spectral time-series, 2D correlation spectroscopy $^{30-32}$ was applied. The software package 2Dshige v1.3 (2Dshige (c) Shigeaki Morita, Kwansei-Gakuin University, 2004-2005) was used to calculate the synchronous and asynchronous 2D correlation plots.

\section{Results and discussion}

\section{Halogen-induced ultra-fine particle formation}

Aerosol formation experiments were conducted for various concentrations of $\alpha$ pinene and chlorine atoms ( $c f$. Table 1). After injecting molecular chlorine into

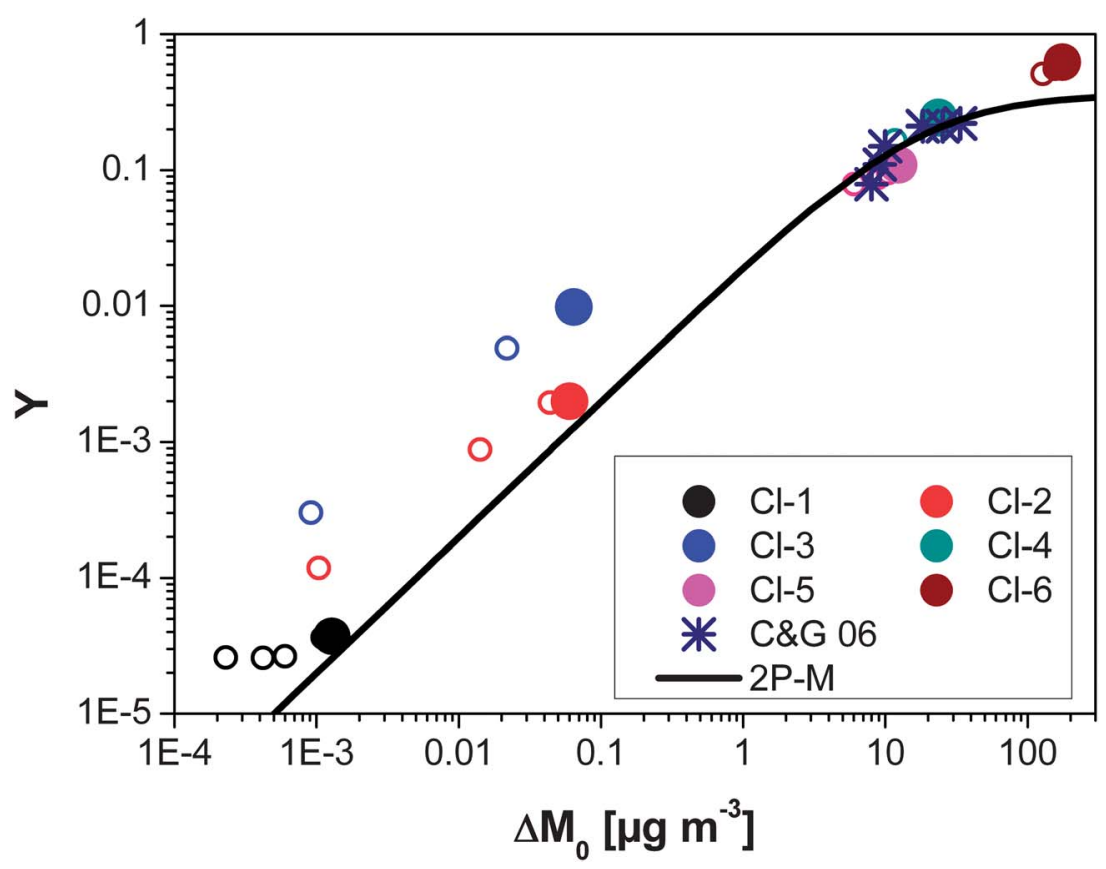

Fig. 3 Yield curves of $\alpha$-pinene and chlorine from six smog-chamber experiments, and yields of six experiments and the yield curve from a two-product model by Cai and Griffin. ${ }^{8}$ For clarity, the lowest yield from $\mathrm{Cl}-3$ is not shown. 


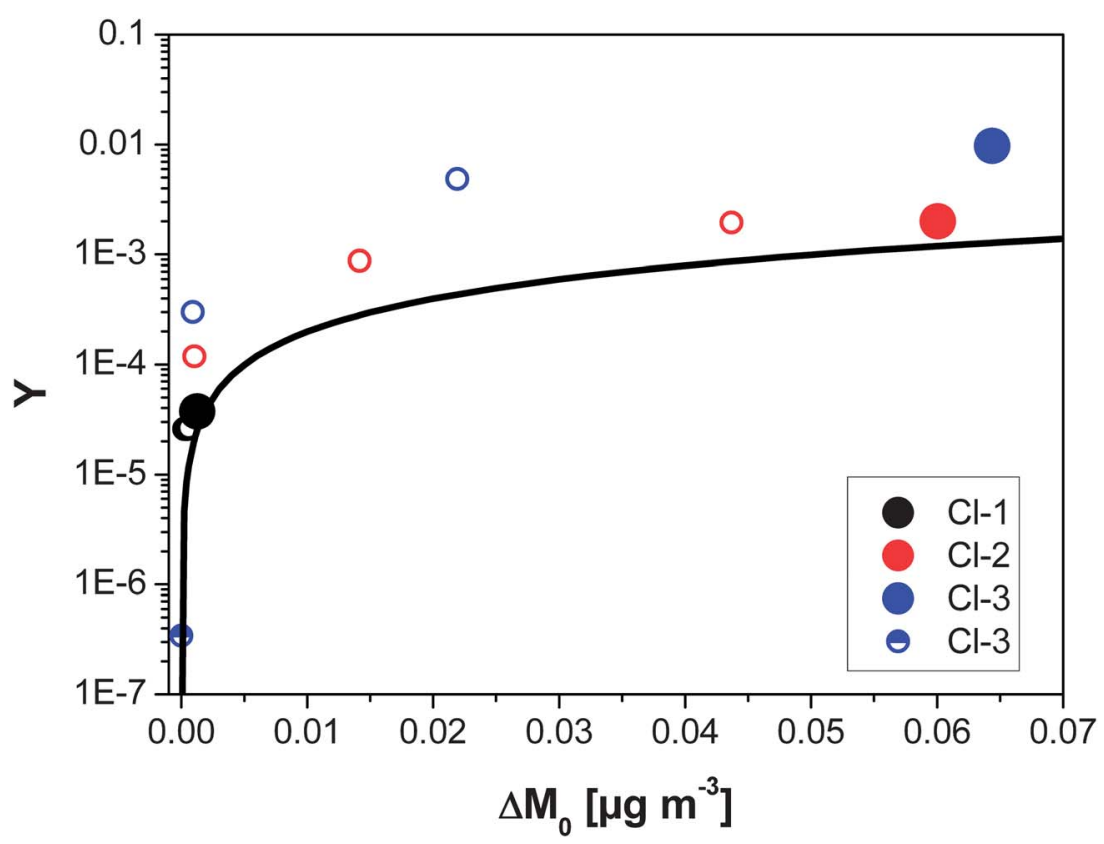

Fig. 4 Closeup of the low concentration experiments $\mathrm{Cl}-1$ to $\mathrm{Cl}-3$.

the illuminated aerosol smog chamber it took about 2 min until the maximum of the particle concentration was reached at low concentrations of the organic precursor and chlorine ( $\mathrm{Cl}-1$ to $\mathrm{Cl}-3$, Table 1 ). In the high concentration experiments (Cl-4 to $\mathrm{Cl}-6$, Table 1$)$, particle formation started immediately after injection. Chlorine mixing ratios as low as $2.5 \mathrm{ppb}$ were sufficient to induce particle formation. The aerosol yield $Y$ was computed as the mass concentration $\Delta M_{0}$ $\left(\mu \mathrm{g} \mathrm{m}^{-3}\right)$ of SOA formed after the organic precursor is completely reacted, divided by the concentration of the reacted organic precursor $\Delta$ VOC $\left(\mu \mathrm{g} \mathrm{m}^{-3}\right)$,

$$
Y=\frac{\Delta M_{0}}{\Delta \mathrm{VOC}}
$$

Following Pandis et al. ${ }^{33}$ in most aerosol formation experiments, $Y$ is evaluated after the organic precursor is completely reacted, gas-particle equilibrium is established, and aerosol growth has stopped. However, several studies have investigated time-dependent aerosol formation, ${ }^{34,35}$ i.e. $\Delta M_{0}$ and $\Delta$ VOC are evaluated frequently in one individual experiment.

In Fig. 3 and 4, we present both the traditional aerosol yield derived from eqn (1) after $\alpha$-pinene is completely reacted (large symbols), and the time-dependent yield curves (small symbols). For comparison, the yields from Cai and Griffin ${ }^{8}$ resulting from six $\alpha$-pinene and chlorine experiments are also included in Fig. 3. Finally, we compare our yields with the yield curve from a two-product model (2P-M) after Odum et al. ${ }^{36}$ parameterized by Cai and Griffin. ${ }^{8}$

We consider the precursor mixing ratios of several ppb of $\alpha$-pinene and chlorine in the experiments $\mathrm{Cl}-1$ to $\mathrm{Cl}-3$ to be within one or two orders of magnitude of typical ambient conditions in coastal environments with biogenic 


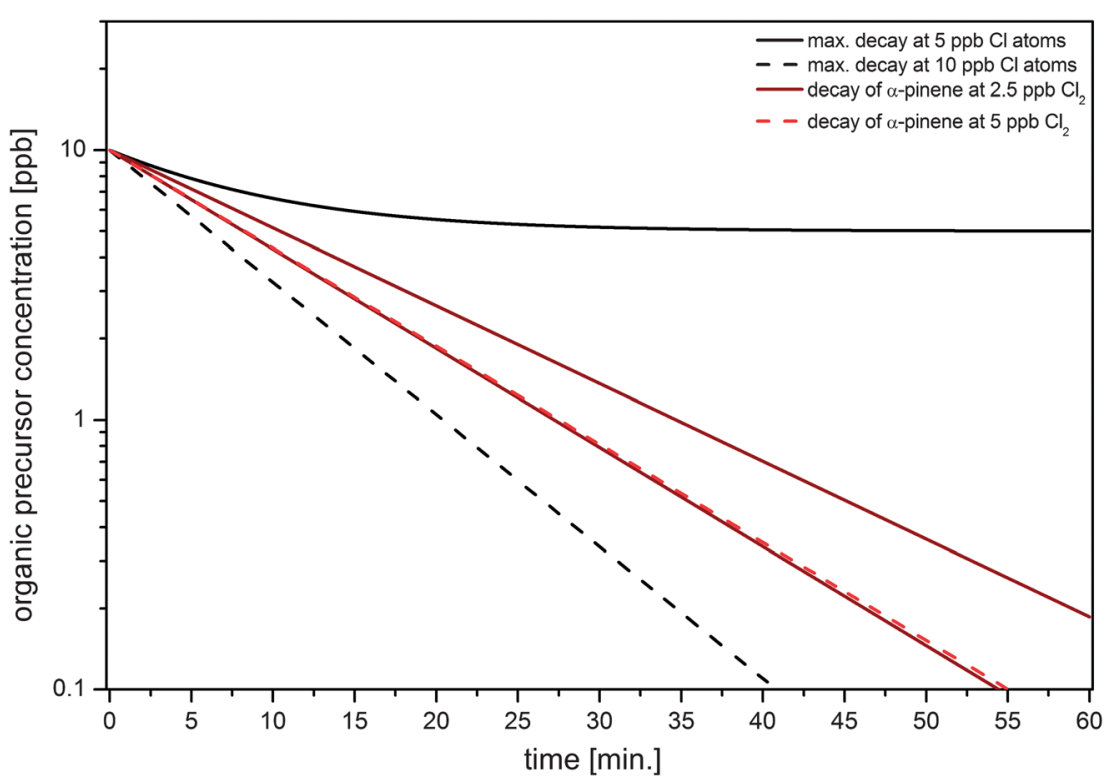

Fig. 5 Calculated maximum and measured decays of the organic precursor based on the available chlorine concentration.

emissions of volatile organic compounds. In any case, these experiments extend previous studies to aerosol mass concentrations almost four orders of magnitude lower than the work by Cai and Griffin. ${ }^{8}$ The yields ranging from 0.0013 to 0.065 are in reasonable agreement with the two-product model shown in Fig. 3 and 4. Precursor mixing ratios in experiments $\mathrm{Cl}-4$ and $\mathrm{Cl}-5$ are similar to the concentration range covered by Cai and Griffin. ${ }^{8}$ Our experiments confirm their results. Higher mixing ratios of $\alpha$-pinene and chlorine in experiment $\mathrm{Cl}-6$ give an aerosol yield higher than expected from the two-product model by Cai and Griffin. ${ }^{8}$

Overall, the observed yields are lower than the yields reported for ozone oxidation of $\alpha$-pinene but larger than yields reported for photooxidation of $\alpha$ pinene (e.g. Griffin et al. $\left.{ }^{37}\right)$. Therefore, the chlorine oxidation mechanism cannot be neglected in environments with high ambient chlorine concentrations.

\section{Halogen consumption and organic precursor decays}

By calculating the decay of available molecular chlorine (based on the chamber actinometry and calculation of the photolysis rate) and subsequently the availability of chlorine atoms, the maximum decay of the organic precursor was calculated. The calculation is based on the simple assumption that every chlorine atom promptly reacts with a molecule of the organic precursor and is not recovered to react with other unprocessed precursor molecules. This maximum decay is compared to the real observed decays of $\alpha$-pinene, obtained from gas chromatography, for the low-concentration experiments (Fig. 5).

As indicated in Fig. 5, the maximum decay consuming all chlorine atoms for the experiments with $2.5 \mathrm{ppb}$ of molecular chlorine would only allow decays from 10 down to $5 \mathrm{ppb}$. The real measured decays are much higher. Tens to hundreds 


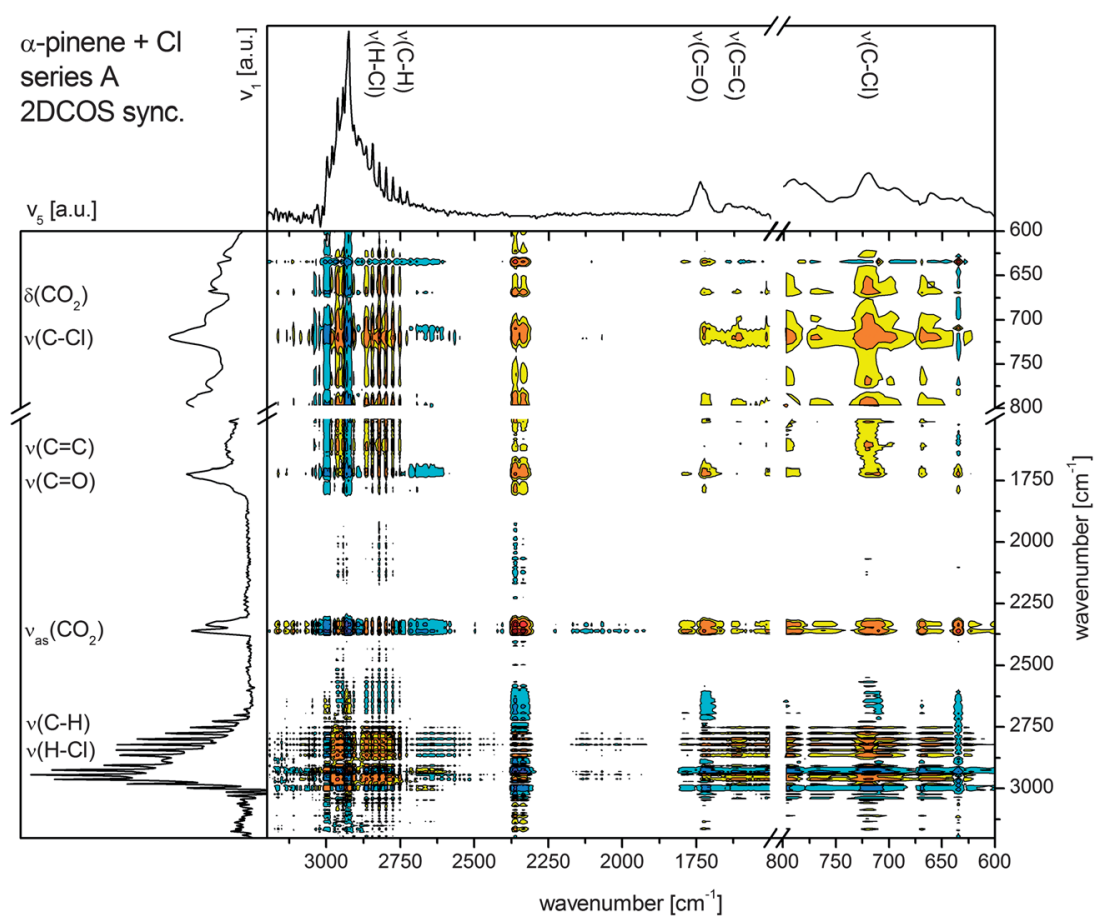

Fig. 6 Synchronous 2D correlation spectroscopy plot of photochemical XOA formation from $\alpha$-pinene with chlorine at condition A, where $\nu_{1}$ is the first obtained spectrum at $1.1 \mathrm{~s}$ and $\nu_{5}$ is the last obtained spectrum at $8.5 \mathrm{~s}$ - yellow to red contours indicate a synchronized change of the signals in the same direction, whereas blue contours indicate a synchronized change of the signals in opposite directions.

of ppt are reached after $60 \mathrm{~min}$, thus, indicating that the basic assumption that chlorine atoms are fully consumed by the same equivalent of organic precursor and not regenerated is inconsistent with the observed reaction behaviour.

For the aerosol smog-chamber experiments, the best agreement of the calculated decay and the measured decay is at $5 \mathrm{ppb}$ of molecular chlorine and $10 \mathrm{ppb}$ of organic precursor. At higher concentrations, the diffusion of the organic precursor and the RHS becomes limiting. XOA formation at low chlorine concentrations appears to be driven by a radical-chain-like reaction mechanism. This is consistent with an initial $\mathrm{Cl}$ addition pathway to alpha-pinene and subsequent opening of the ring leading to pinonaldehyde and release of $\mathrm{Cl}$ as proposed by Cai and Griffin. ${ }^{8}$ A major limiting factor is the diffusivity of the gaseous species.

\section{Chemical transformation of XOA during the formation and aging process}

Chemical details on XOA formation were obtained from the aerosol flow-reactor experiments, where each series is represented by 5 single experiments at different times of the reaction. The general interpretation of the FTIR spectra and 2D correlation plots is related to the FTIR spectrum of pure $\alpha$-pinene. ${ }^{38}$ Spectra of the aerosol flow-reactor conditions A and C (Table 2) represent the highest spectral changes, thus these two time series were interpreted in detail. Condition A allows 


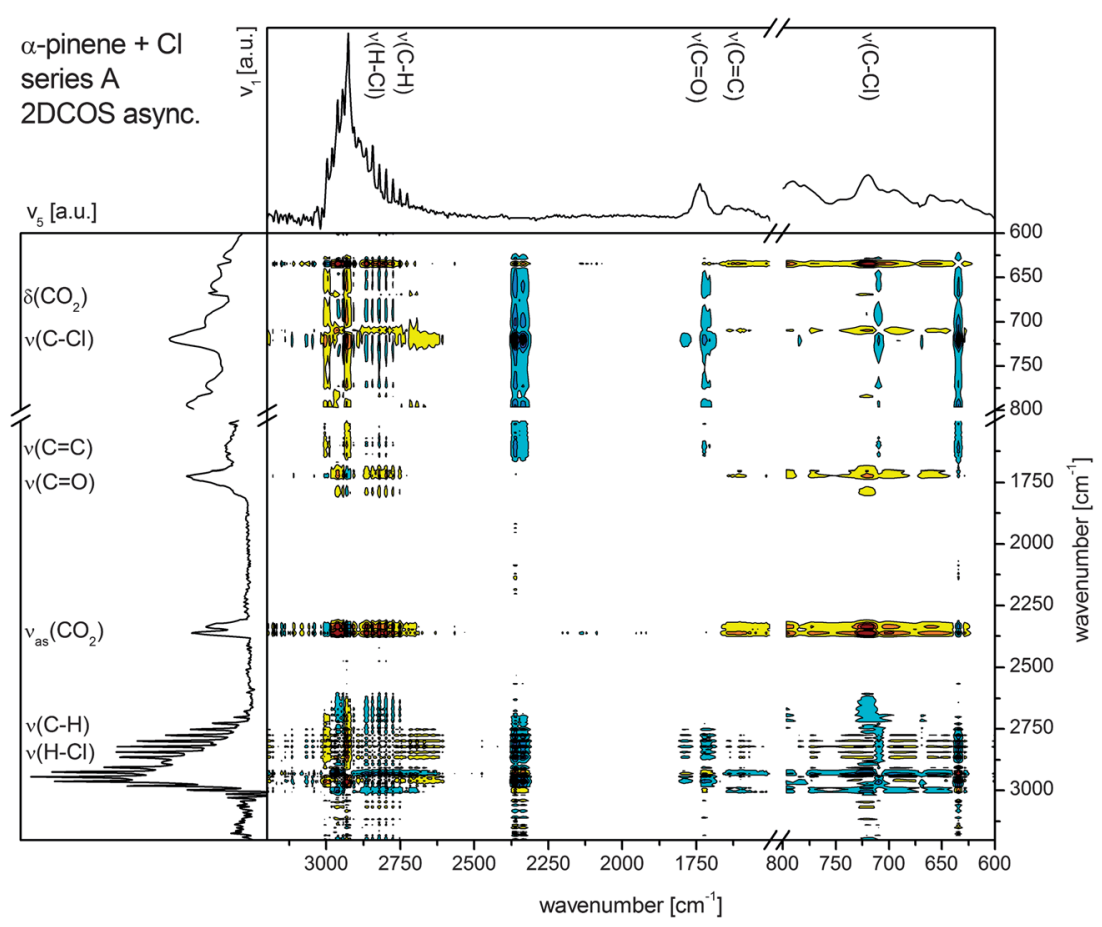

Fig. 7 Asynchronous 2D correlation spectroscopy plot of XOA formation from photochemical reactions of $\alpha$-pinene with chlorine at condition A, where $\nu_{1}$ is the first obtained spectrum at $1.1 \mathrm{~s}$ and $\nu_{5}$ is the last obtained spectrum at $8.5 \mathrm{~s}$ - yellow to red contours indicate a change of absorption in $\nu_{1}$ before $\nu_{5}$, whereas blue contours indicate the other way round.

temporal steps of 1.1, 2.1, 4.2, 6.3 and $8.5 \mathrm{~s}$ (related to the distance of the inlet to the centre of the multi-reflection cell - see section 2 Methods), condition C of 1.4, $2.9,5.8,8.7$ and $11.5 \mathrm{~s}$. The $2 \mathrm{D}$ correlation of the fast condition $\mathrm{A}$ is more sensitive towards changes related to the gaseous species like $\mathrm{HCl}$ and $\mathrm{CO}_{2}$. The slower condition $\mathrm{C}$ exhibits significant changes related to the aerosol particle phase like changes of the $\nu(\mathrm{C}=\mathrm{O}), \nu(\mathrm{C}=\mathrm{C}), \nu(\mathrm{C}-\mathrm{H})$ and the $\nu(\mathrm{C}-\mathrm{Cl})$ stretch vibrations. While the temporal starting point of both series should be rather similar, significant differences (e.g. in the $v(\mathrm{C}=\mathrm{O})$ spectral region) are visible. These differences can be explained by changing flow conditions, different concentration profiles and a different behaviour of the laminar flow profile and the related mixing inside the flow reactor.

As mentioned above, the 2D correlation spectroscopy plots (Fig. 6 and 7) of the photochemical XOA formation from $\alpha$-pinene with chlorine at aerosol flowreactor condition A appear to be more sensitive to the gaseous species. The synchronous plot (Fig. 6) indicates a coupling of $\mathrm{CO}_{2}\left(\nu_{\mathrm{as}}(\mathrm{C}=\mathrm{O})\right.$ at $\left.2349 \mathrm{~cm}^{-1}\right)$ and $\mathrm{HCl}$ (narrow absorptions between 2700-3100 $\mathrm{cm}^{-1}$ ) formation. The aerosol formation itself is also correlated with the formation of carbon chlorine bonds $\left(\nu(\mathrm{C}-\mathrm{Cl})\right.$ at $\left.720 \mathrm{~cm}^{-1}\right)$, by addition of chlorine to the $\mathrm{C}=\mathrm{C}$ double bond or to a radical site, and of carbonyls and/or carboxylic acids $(\nu(\mathrm{C}=\mathrm{O})$ at $1700-$ $\left.1750 \mathrm{~cm}^{-1}\right)$. The synchronous plot exhibits an anti-correlation of the aliphatic $\nu(\mathrm{C}-\mathrm{H})$ of the $-\mathrm{CH}_{3}$ groups of $\alpha$-pinene $\mathrm{e}^{38}$ at $2995 \mathrm{~cm}^{-1}$ and $2925 \mathrm{~cm}^{-1}$ with the 


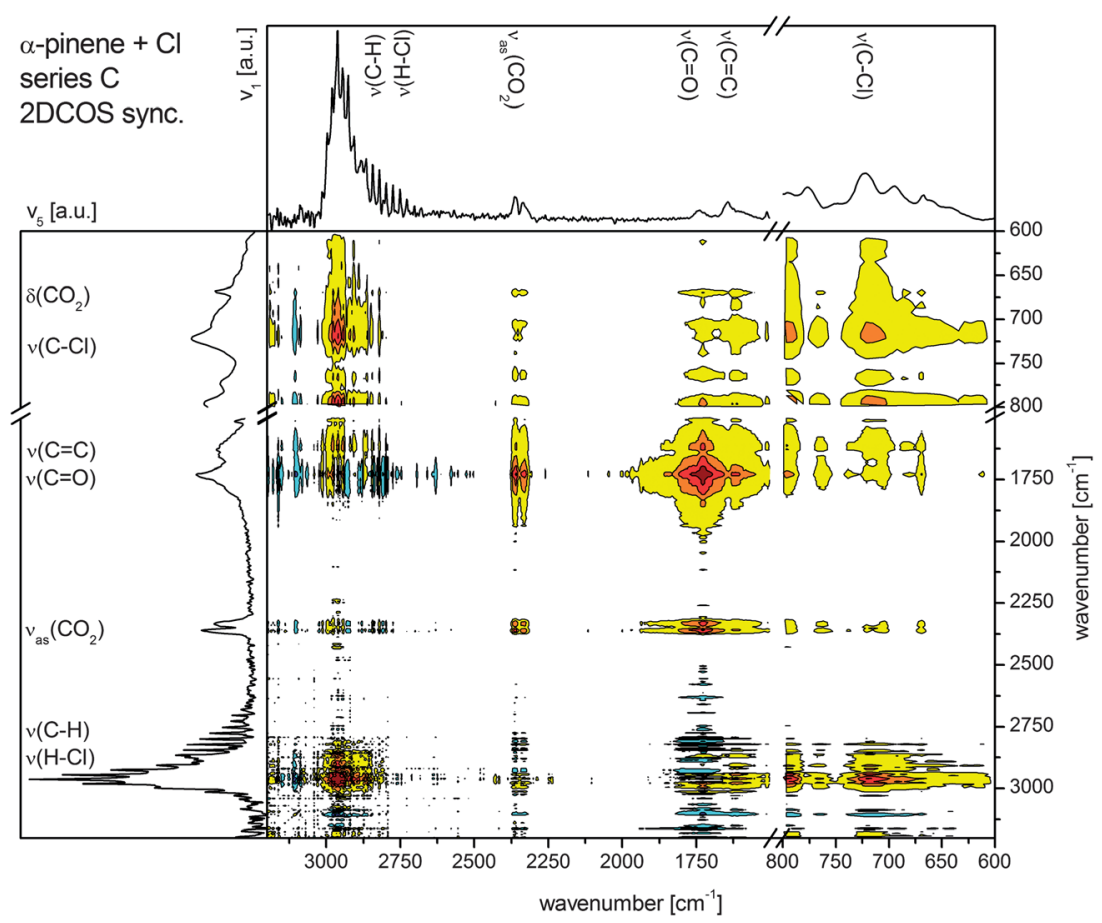

Fig. 8 A synchronous 2D correlation spectroscopy plot of photochemical XOA formation from $\alpha$-pinene with chlorine at condition $C_{;} \nu_{1}$ at $1.4 \mathrm{~s}$ and $\nu_{5}$ at $11.5 \mathrm{~s}$.

overall aerosol formation (which is caused by a halogen-induced abstraction of hydrogen atoms).

Details on the sequence of transformation of single absorptions and species are given by the 2D asynchronous plot (Fig. 7). The sequential order was interpreted according to the so-called "Noda" rules. ${ }^{22}$ No asynchronous cross-peaks exist in case of the absorptions of the $\mathrm{C}-\mathrm{Cl}$ bond formation and the $\mathrm{HCl}$ release (which is indicated in the synchronous plot by positive cross-peaks). The formation of halogenated species in the aerosol phase is synchronous and thus coupled to the release of $\mathrm{HCl}$ to the gas phase. Due to the fact that the synchronous crosspeaks between $\mathrm{CO}_{2}$ and the $\mathrm{C}-\mathrm{Cl}$ formation are positive and asynchronous crosspeaks exist, the $\mathrm{CO}_{2}$ release is following the $\mathrm{C}-\mathrm{Cl}$ formation and $\mathrm{HCl}$ release. Missing asynchronous cross-peaks between the $\nu(\mathrm{C}=\mathrm{O})$ and the release of $\mathrm{CO}_{2}$ indicate a synchronous coupling of the formation of carbonyls or carboxylic acids and the release of $\mathrm{CO}_{2}$. The sequence of $\nu(\mathrm{C}-\mathrm{Cl})$ formation with $\mathrm{HCl}$ release and following $\mathrm{C}=\mathrm{O}$ bond formation is also indicated by the asynchronous cross-peaks between $\mathrm{HCl}$ and $\nu(\mathrm{C}=\mathrm{O})$ and $\nu(\mathrm{C}-\mathrm{Cl})$ and $\nu(\mathrm{C}=\mathrm{O})$.

In contrast to series A, plots from series $\mathrm{C}$ appear to be more sensitive towards changes of the formed aerosol phase. The synchronous plot of $2 \mathrm{D}$ correlation spectroscopy in Fig. 8 exhibits strong auto-correlation peaks related to the formation of carbonyls and/or carboxylic acids $\left(\nu(\mathrm{C}=\mathrm{O})\right.$ at $\left.1700-1750 \mathrm{~cm}^{-1}\right)$ and to the formation of carbon chlorine bonds at $720 \mathrm{~cm}^{-1}$. Further changes are visible in case of the olefinic $\nu(\mathrm{C}=\mathrm{C})$ stretch vibration, which appears to broaden, caused by the formation of oligomers and more complex species. While the 


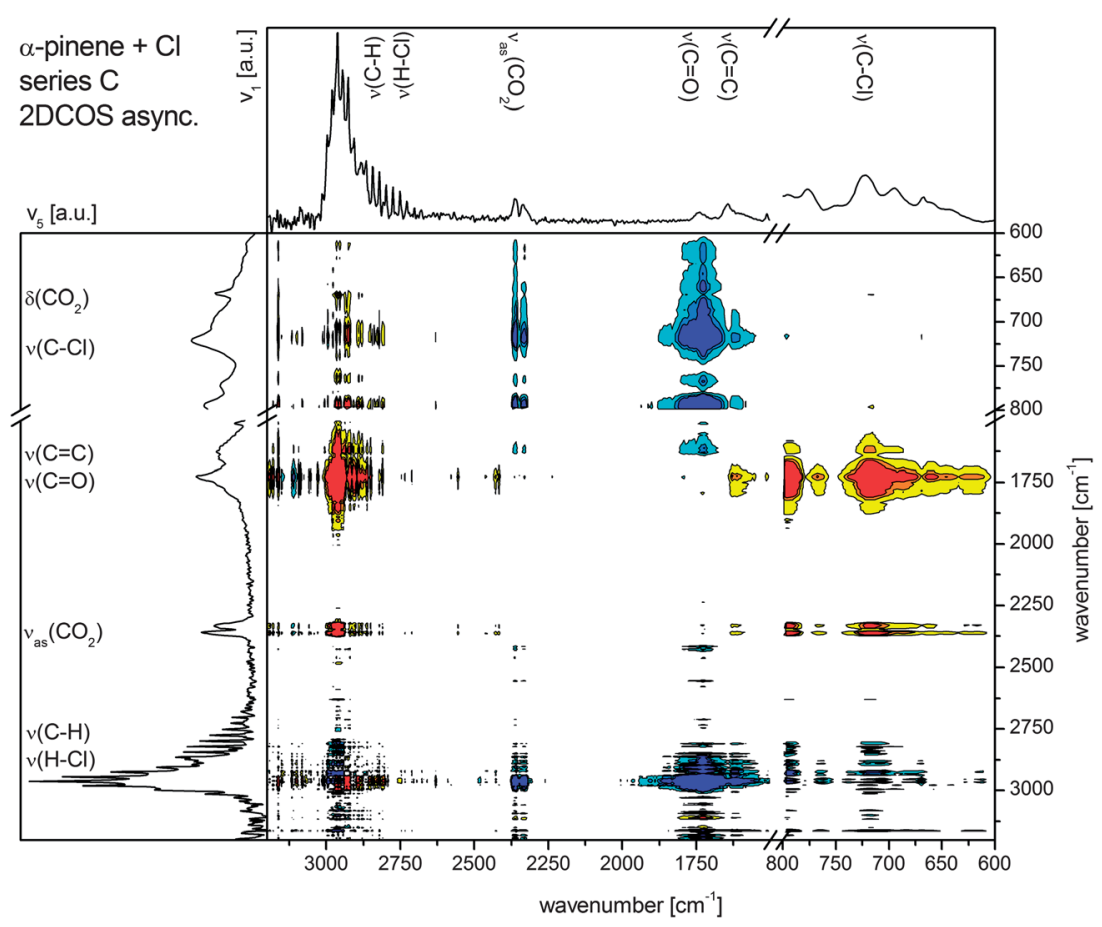

Fig. 9 Asynchronous 2D correlation spectroscopy plot of photochemical XOA formation from $\alpha$-pinene with chlorine at condition $C_{;} \nu_{1}$ at $1.4 \mathrm{~s}$ and $\nu_{5}$ at $11.5 \mathrm{~s}$.

degradation of the well-defined $\nu(\mathrm{C}-\mathrm{H})$ stretch vibration in Fig. 8 is not visible like in Fig. 6, a general broadening of the aliphatic carbon hydrogen bond regime is observed. This broadening, which appears like carbon-hydrogen bond formation, can be related to the formation and aging of particulate matter.

The sequence of the gaseous species is similarly demonstrated in the asynchronous plot of series C (Fig. 9). The formation of carboxylic acids or carbonyls follows after $\mathrm{C}-\mathrm{Cl}$ formation. Also the transformation of the $\operatorname{sharp} \nu(\mathrm{C}=\mathrm{C})$ stretch vibration of the organic precursor (around $1650 \mathrm{~cm}^{-1}$ ) to the broad absorption of various olefinic structures within the particulate phase takes place before $\nu(C=O)$ formation. The broad asynchronous cross-peaks between 600 and $800 \mathrm{~cm}^{-1}$ indicate the formation of a broad finger-print region. This can be related to the formation of oligomers and high-molecular structures or a large variety of different organic species.

The general roadmap of XOA formation, initiated by addition of chlorine and $\mathrm{H}$ atom abstraction, forming $\mathrm{HCl}$ and chlorine carbon bonds is in good agreement with the studies by Cai and Griffin ${ }^{8}$ and Karlsson et al. ${ }^{7}$ Also, the subsequent addition of oxygen to the so formed radical sites of the organic structure and the coupled formation of carbonyls and carboxylic acids, as well as the concurrent release of $\mathrm{CO}_{2}$, is in agreement with the suggestions made by these authors. During further processing, the freshly formed XOA appears to degrade and becomes more SOA-like, losing the halogen-induced characteristics and appearing more "common". 


\section{Conclusions}

Reactive halogen species releasing $\mathrm{Cl}$ radicals can induce organic aerosol formation by reaction with organic precursor gases, such as $\alpha$-pinene. From the experiments in this work evidence is found both for a $\mathrm{Cl}$ addition pathway to $\alpha$-pinene as well as an $\mathrm{H}$-atom abstraction pathway. On one hand, the formation of $\mathrm{C}-\mathrm{Cl}$ bonds in the FTIR spectra as well as indirect evidence for a radical-chain mechanism ( $c f$. Fig. 5) is consistent with $\mathrm{Cl}$ addition. On the other hand, the formation of $\mathrm{HCl}$ observed in the flow-reactor experiments is consistent with $\mathrm{H}$-atom abstraction in the reaction between $\mathrm{Cl}$ and $\alpha$-pinene. ${ }^{15}$ However, it is difficult to quantify the respective contributions of these pathways to the overall reaction.

The aerosol yield found in low and high concentration experiments is in general agreement with previous experimental data by Cai and Griffin ${ }^{8}$ as well as a parameterization of the yield curve presented by the same authors. Even at precursor concentrations almost four orders of magnitude lower than the previous experiments, a reasonable agreement with the two-product parameterization is found. With a broad range of mixing ratios of $\alpha$-pinene and chlorine in six experiments we could extend the data from these authors and obtain aerosol formation yields even at close-to-ambient conditions.

The chemical formation of this type of organic aerosol is halogen driven as demonstrated by the aerosol flow-reactor experiments. The formation process occurs in the absence of ozone but also even without oxygen. Thus, the formation of halogen-induced organic aerosol represents an aerosol formation process apart from the commonly considered formation pathways. The further processing of XOA with oxygen and oxygen-containing reactants causes a transformation of XOA to the common SOA which is dominated by oxygen-containing functional groups. This XOA-born SOA still exhibits carbon-chlorine bonds, thus indicating the XOA-like source of the organic aerosol. With further chemical aging and processing by atmospheric reactive species, the XOA-like character of the organic aerosol from monoterpenes and RHS is lost.

The formation of XOA from monoterpenes or other organic volatile species with RHS must not be neglected for e.g. maritime areas, where high RHS and VOC concentrations occur at dawn or sunset simultaneously. Although XOA appears to be transformed to SOA by aging and processing, this special type of organic aerosol might exhibit different features not commonly related to SOA or the organic aerosol in general. The halogen-driven formation and the coupled formation of solid halogen species in the particle phase significantly influences physico-chemical parameters like water-solubility, the potential to act as cloud condensation or ice nuclei, the adsorption behaviour with respect to gas-phase species as well as the interaction with sunlight (or the UV/VIS absorption spectrum $\left.{ }^{10}\right)$. This changes the influence on radiative forcing and thus modifies the influence of XOA on global warming compared to commonly considered SOA.

\section{Acknowledgements}

The authors would like to thank the German research foundation for funding within the research unit HaloProc (HE5214/5-1 and ZE792/5-2). Further the authors thank Georg Ramer from the Institute of Chemical Technologies and Analytics, Vienna University of Technology for his assistance in 2D correlation spectroscopy. 


\section{References}

1 J. H. Kroll and J. H. Seinfeld, Atmos. Environ., 2008, 42, 3593-3624.

2 J. L. Jimenez, M. R. Canagaratna, N. M. Donahue, A. S. H. Prevot, Q. Zhang, J. H. Kroll, P. F. DeCarlo, J. D. Allan, H. Coe, N. L. Ng, A. C. Aiken, K. S. Docherty, I. M. Ulbrich, A. P. Grieshop, A. L. Robinson, J. Duplissy, J. D. Smith, K. R. Wilson, V. A. Lanz, C. Hueglin, Y. L. Sun, J. Tian, A. Laaksonen, T. Raatikainen, J. Rautiainen, P. Vaattovaara, M. Ehn, M. Kulmala, J. M. Tomlinson, D. R. Collins, M. J. Cubison, E. J. Dunlea, J. A. Huffman, T. B. Onasch, M. R. Alfarra, P. I. Williams, K. Bower, Y. Kondo, J. Schneider, F. Drewnick, S. Borrmann, S. Weimer, K. Demerjian, D. Salcedo, L. Cottrell, R. Griffin, A. Takami, T. Miyoshi, S. Hatakeyama, A. Shimono, J. Y. Sun, Y. M. Zhang, K. Dzepina, J. R. Kimmel, D. Sueper, J. T. Jayne, S. C. Herndon, A. M. Trimborn, L. R. Williams, E. C. Wood, A. M. Middlebrook, C. E. Kolb, U. Baltensperger and D. R. Worsnop, Science, 2009, 326, 1525-9.

3 I. Riipinen, T. Yli-Juuti, J. R. Pierce, T. Petäjä, D. R. Worsnop, M. Kulmala and N. M. Donahue, Nat. Geosci., 2012, 5, 453-458.

4 C. O’Dowd, M. Facchini, F. Cavalli, D. Ceburnis, M. Mircea, S. Decesari, S. Fuzzi, Y. J. Yoon and J.-P. Putaud, Nature, 2004, 431, 676-680.

5 L. J. Carpenter, S. D. Archer and R. Beale, Chem. Soc. Rev., 2012, 41, 6473-506.

6 Q. K. Timerghazin and P. A. Ariya, Phys. Chem. Chem. Phys., 2001, 3, 3981-3986.

7 R. S. Karlsson, J. J. Szente, J. C. Ball and M. M. Maricq, J. Phys. Chem. A, 2001, 105, 82-96.

8 X. Cai and R. J. Griffin, J. Geophys. Res., 2006, 111, D14206.

9 X. Cai, L. D. Ziemba and R. J. Griffin, Atmos. Environ., 2008, 42, 7348-7359.

10 J. Ofner, N. Balzer, J. Buxmann, H. Grothe, P. Schmitt-Kopplin, U. Platt and C. Zetzsch, Atmos. Chem. Phys., 2012, 12, 5787-5806.

11 J. H. Kroll, N. M. Donahue, J. L. Jimenez, S. H. Kessler, M. R. Canagaratna, K. R. Wilson, K. E. Altieri, L. R. Mazzoleni, A. S. Wozniak, H. Bluhm, E. R. Mysak, J. D. Smith, C. E. Kolb and D. R. Worsnop, Nat. Chem., 2011, 3, 133-9.

12 T. Moise and Y. Rudich, Geophys. Res. Lett., 2001, 28, 4083-4086.

13 R. C. Sullivan and K. A. Prather, Anal. Chem., 2005, 77, 3861-85.

14 D. Vione, V. Maurino, S. C. Man, S. Khanra, C. Arsene, R.-I. Olariu and C. Minero, ChemSusChem, 2008, 1, 197-204.

15 B. J. Finlayson-Pitts, C. J. Keoshian, B. Buehler and A. A. Ezell, Int. J. Chem. Kinet., 1999, 31, 491-499.

16 B. J. Finlayson-Pitts, Res. Chem. Intermed., 1993, 19, 235-249.

17 C. Spicer and E. Chapman, Nature, 1998, 1996, 1996-1999.

18 A. Saiz-Lopez and R. von Glasow, Chem. Soc. Rev., 2012, 41, 6448-72.

19 C. Zetzsch and W. Behnke, NATO ASI Ser., Ser. I, 1993, 7, 291-306.

20 B. J. Finlayson-Pitts, Chem. Rev., 2003, 103, 4801-22.

21 J. A. Thornton, J. P. Kercher, T. P. Riedel, N. L. Wagner, J. Cozic, J. S. Holloway, W. P. Dubé, G. M. Wolfe, P. K. Quinn, A. M. Middlebrook, B. Alexander and S. S. Brown, Nature, 2010, 464, 271-4.

22 I. Noda, Generalized Two-Dimensional Correlation Spectroscopy in Frontiers of Molecular Spectroscopy, ed. Jaan Laane, Elsevier, 2009, ISBN: 978-0-444-53175.

23 J. Ofner, H.-U. Krüger, H. Grothe, P. Schmitt-Kopplin, K. Whitmore and C. Zetzsch, Atmos. Chem. Phys., 2011, 11, 1-15.

24 B. Bohn, F. Rohrer, T. Brauers and A. Wahner, Atmos. Chem. Phys., 2005, 5, 493-503.

25 A. Ruggaber, R. Dlugi and T. Nakajima, J. Atmos. Chem., 1994, 18, 171-210.

26 R. K. Pathak, C. O. Stanier, N. M. Donahue and S. N. Pandis, J. Geophys. Res., 2007, 112, D03201.

27 J. G. Crump and J. H. Seinfeld, J. Aerosol Sci., 1981, 12, 405-415.

28 J. Ofner, H.-U. Krüger and C. Zetzsch, Appl. Opt., 2010, 49, 5001.

29 J. Ofner, H.-U. Krüger and C. Zetzsch, Z. Phys. Chem., 2010, 224, 1171-1183.

30 I. Noda, Appl. Spectrosc., 1993, 47, 1329-1336.

31 I. Noda, A. Dowrey and C. Marcott, Appl. Spectrosc., 2000, 54, 236A-248A.

32 B. Muik, B. Lendl, A. Molina-Diaz, M. Valcarcel and M. J. Ayora-Cañada, Anal. Chim. Acta, 2007, 593, 54-67.

33 S. N. Pandis, R. A. Harley, G. R. Cass and J. H. Seinfeld, Atmos. Environ., Part A, 1992, 26, 2269-2282.

34 T. Hoffmann, J. Odum, F. Bowman, D. Collins, D. Klockow, R. C. Flagan and J. H. Seinfeld, J. Atmos. Chem., 1997, 26, 189-222.

35 N. L. Ng, J. H. Kroll, M. D. Keywood, R. Bahreini, V. Varutbangkul, R. C. Flagan, J. H. Seinfeld, A. Lee and A. H. Goldstein, Environ. Sci. Technol., 2006, 40, 22832297. 
36 J. R. Odum, T. Hoffmann, F. Bowman, D. Collins, R. C. Flagan and J. H. Seinfeld, Environ. Sci. Technol., 1996, 30, 2580-2585.

37 R. J. Griffin, D. R. Cocker, R. C. Flagan and J. H. Seinfeld, J. Geophys. Res., 1999, 104, 3555. 38 H. W. Wilson, Appl. Spectrosc., 1976, 30, 209-212. 